\title{
PROBLEMAS E PERSPECTIVAS dA PARTICIPAÇÃO DE ESTADOS E ENTIDADES PÚBLICAS ENQUANTO PARTES NO JUÍZO ARBITRAL
}

Melina Girardi Fachin ${ }^{1}$

\section{RESUMO}

A arbitragem, em especial a arbitragem comercial internacional, é campo de estudo em ascensão na contemporaneidade. $O$ espectro de possibilidades abarcado pelo gênero arbitragem comercial internacional é extremamente amplo. Abareadas neste conjunto de possibilidades estão as arbitragens que envolvem a participação crescente dos Estados, em especial daqueles menos desenvolvidos economicamente. Deste modo, observa-se a submissão da figura estatal ao capital privado internacional tendo em vista a necessidade de convenção de desenvolvimento.

\section{ABSTRACT}

The arbitration,specially the international commercial one, is a field of studies that has currently been going up. The specter of possibilities reached by this kind of international commercial arbitration is extremely wide. Inside this set of possibilities are the arbitrations which comprise the increasing participation of the States, mainly the less economically developed ones.In this way, the state figure, submitted to the international private capital is observed, due to the necessity of development agreements.

PALAVRAS-CHAVE: Arbitragem - Estado - Interesse Público.

KEY-WORDS: Arbitration - State - Public Interest.

\footnotetext{
${ }^{1}$ Graduada em Direito pela UFPR, mestranda em Filosofia pela PUC-SP.
}

Revista Brasileira de Direito Internacional, Curitiba, v.2, n.2, jul./dez.2005 


\section{INTRODUÇÃO}

O presente trabalho se ocupa de reflexão crítica e construtiva que, resgatando elementos históricos que se projetam na contemporaneidade, expõe idéias e dilemas que desafiam a compreensão da participação de entes estatais em juízo arbitral comercial internacional.

Para tanto, alicerçado nos marcos teóricos adiante explicitados, se divide em três partes estruturantes, as quais, a seu turno, se subdividem em diversos itens que têm como objetivo desenvolver a temática eleita e propiciar, ao final, uma síntese à guisa de conclusão.

A primeira parte destina-se ao estudo dos apontamentos e problemas concernentes a formulação teórica que envolve esta temática.

Em um segundo momento, o estudo será voltado para a prática da $\mathrm{CCl}$ (Câmara de Comércio Internacional) nas ocorrências que envolvam Estados ou entidades públicas como partes em juízo arbitral.

Por fim, em sua derradeira parte, o trabalho objetiva visualizar esta temática a guisa do direito nacional, utilizando como metodologia para tal a avaliação de um caso concreto.

Esboçado o itinerário a ser caminhado no presente trabalho, faz-se necessária a delimitação, em linhas gerais, da arbitragem de Estados à guisa de introdução.

A arbitragem comercial internacional é campo de estudo "transversal e interdisciplinar"2. A complexidade da matéria espelha diretamente a influência direta das diversas áreas do conhecimento, dentre e fora da seara jurídica.

Em consonância com a lição de Oppetit ${ }^{3}$ :

A atração que suscitam a prática e o estudo da arbitragem comercial
internacional nos juristas não se deve unicamente aos interesses materiais,
muitas vezes consideráveis, que estão em jogo; ela se explica igualmente,
para uma parte não negligenciável, pela sedução intelectual que exerce sobre
os espíritos uma noção situada na intersecção de quase todas as disciplinas
jurídicas, tanto de direito substancial como de metodologia, o que impede o

${ }^{2}$ ROMERO, E.S. A Arbitragem da Câmara de Comércio Internacional e os Contratos de Estado. In: Revista de Direito Bancário do Mercado de Capitais e da Arbitragem $n^{\circ} 19$. São Paulo: RT, jan-mar de 2003.

${ }^{3}$ OPPETIT, B. Théorie de l'arbitrage. Paris: PUF, 1998. p. 109.

Revista Brasileira de Direito Internacional, Curitiba, v.2, n.2, jul./dez.2005 
estreitamento muito freqüentemente ocasionado nos dias de hoje pela excessiva especialização e pela estreita tecnicização, que se tornaram as tendências dominantes da doutrina moderna. Ademais: a arbitragem comercial internacional, por sua própria problemática, só pode resolver as inúmeras dificuldades que se lhe apresentam por meio de uma reflexão sobre as questões mais fundamentais suscetíveis de serem verificadas no âmbito de um sistema jurídico: a justiça, suas formas e seus objetivos, a juridicidade, suas fontes e sua natureza, a estrutura da ordem jurídica, as finalidades do direito.

O espectro de possibilidades abarcado pelo gênero arbitragem comercial internacional é extremamente amplo. Abarcadas neste conjunto de possibilidades estão as arbitragens exclusivamente entre estados acerca de disputas comerciais, perpassando por aqueles contratos entre Estado e particulares e aquelas convenções, de configuração mais corriqueira, entre particulares. Destacamos, dentre esta gama, a participação do Estado enquanto parte em juízos arbitrais.

A participação dos Estados em contratos e acordos comerciais internacionais é crescente. Esta margem apresenta um crescimento ainda maior quando se diz respeito aos países menos desenvolvidos. Destarte, a inclusão no mercado global é condição necessária tendo em vista a dependência econômica externa, especialmente acentuada nestes países.

Desta feita afirma José Carlos de Magalhães que "se, de um lado, há o desejo de preservar a independência política, de outro, há o reconhecimento de que a independência econômica e tecnológica não foi conseguida e que é necessário contar com capitais e técnicas dos investidores estrangeiros"4.

Neste influxo, assevera Prosper Weil:

\begin{abstract}
A submissão do contrato ao direito interno e aos juízes nacionais, não obstante não evite sejam acionados mecanismos internacionais, como a proteção diplomática, não assegura garantia suficiente ao contratante. Essa proteção, no entanto, é necessária e o próprio Estado está interessado em concede-la, como forma de garantir o fluxo de investimentos estrangeiros e acordos de desenvolvimento. Há, portanto, tendência à liberalização das relações contratuais, com a caracterização da igualdade jurídica das partes, predispondo-as a aceitar normas internacionais e a submissão de litígios à arbitragem internacional.
\end{abstract}

Deste modo, observa-se a submissão da figura estatal ao capital privado internacional tendo em vista a necessidade do fluxo de investimentos 
estrangeiros e acordos de desenvolvimento. É neste diapasão que autores como Mann ${ }^{5}$ afirmam que, ao admitir cláusula arbitral em seus contratos, o Estado adota as características de entidade privada despindo-se de suas prerrogativas e vicissitudes. Para Pontes de Miranda ${ }^{6}$ no momento em que 0 Estado admite o juízo arbitral ele automaticamente abdica da jurisdição estatal interna.

\section{CONTORNOS DA ARBITRAGEM: (IM)POSSIBILIDADE DA PARTICIPAÇÃO ESTATAL}

\subsection{SUJEITOS DA ARBITRAGEM}

As arbitragens que envolvem entidades de direito público podem envolver exclusivamente partes estatais ou desenrolarem-se entre uma parte estatal e outra particular.

As arbitragens entre estados não são usualmente concebidas puramente enquanto disputas comerciais. Entretanto, sua prática acabou por influenciar os próprios institutos e procedimentos da arbitragem comercial internacional contemporânea.

Ainda no final do XIX, as arbitragens entre Estados logravam algum êxito através da Corte Permanente de Arbitragem. Todavia, hodiernamente, esta Corte desconfigurou-se uma vez que não há efetivamente um Tribunal corporificado e estruturado estável.

Nas palavras de Redfern e Hunter, "the work load of the PCA (Permanent Court of Arbitration) has been low. No doubt many disputes which arise between states are political in origin and demand political rather than judicial solutions (...)". 7

A ênfase, todavia, da participação dos Estados na arena internacional

\footnotetext{
${ }^{4}$ MAGALHÃES, J. C. Arbitragem Comercial. Rio de Janeiro: Freitas Bastos. 1986. p. 69.

5 MANN, F. A. State Contracts and International Arbitration. Nova lorque: Studies of International Law, s.d.. p. 257.

${ }_{7}^{6}$ PONTES DE MIRANDA. Tratado de Direito Privado. v. 26. p. 3.121.

7 HUNTER, M.e REDFERN, A. Law and Pratice of International Commercial Arbitration. London: Sweet \& Maxwell, 1986. p. 29.
}

Revista Brasileira de Direito Internacional, Curitiba, v.2, n.2, jul./dez.2005 
está justamente nos acordos de vontade firmados com partes particulares ou privadas, geralmente corporações transnacionais.

É estimado que ao menos um terço das arbitragens conduzidas sob o crivo da $\mathrm{CCl}$ envolvem estados ou entidades estatais como parte. ${ }^{8}$

Nesta toada, tendo em vista a importância e ampliação progressivo da prática arbitral envolvendo Estados, faz-se relevante delineação dos apontamentos e problemas concernentes a formulação teórica deste tema.

\subsection{AS CORRENTES DOUTRINÁRIAS ACERCA DA ARBITRAGEM EM CONTRATOS DE ESTADO}

A doutrina enuncia alguns riscos ${ }^{9}$ resultantes da participação de entidades estatais ou públicas no juízo arbitral. Esta instabilidade avulta especialmente quando se tratam de procedimentos de arbitragem comercial internacional envolvendo pessoas jurídicas de direito público. Ou seja, nas hipóteses em que hajam contratos de estado submetidos ao procedimento arbitral.

Os ditos contratos de estado são aqueles "concluídos entre um Estado soberano e uma pessoa privada"10. Em face desta conjuntura, chocam-se dois interesses: um econômico, outro político.

Conforme afirma a doutrina:

Many factors must be weighed in the scale when a state considers whether or not to submit to arbitration. There are political considerations, such as the effect which a refusal to go ahead with arbitration might have on relations with the state to which the foreign claimant belongs. There are also economic considerations, such as the loss of foreign investment which a refusal to arbitrate might bring about. There are legal considerations - such as the effect of an award being granted in absentia $(. . .)^{11}$

É justamente da defesa de cada um destes interesses que se sobressaem as teorias colidentes acerca da arbitragem internacional em questões de Estado.

\footnotetext{
${ }^{8}$ Ibid. p. 30.

${ }^{9}$ OPPETIT, B. Ibid.

${ }^{10}$ CORNU, G. Vocabulaire Juridique. Paris: PUF, 2003. p. 223.
} 


\subsubsection{A Posição Econômica}

Esta corrente de pensamento encontra grande respaldo, em especial, dentro os doutrinadores privatísticos.

Destarte, a arbitragem comercial envolvendo pessoas de direito público deve ser visualizada enquanto uma hipótese normal do procedimento arbitral. Para estes autores, na ocasião em que Estado, ou alguns de seus entes ou órgãos diretos e indiretos, toma parte no comércio internacional, este lança mão da posição diferenciada que geralmente the confere os ordenamentos internos.

Sob este olhar, não passa o Estado de um operador econômico normal que deve se submeter, como o restante da comunidade econômica internacional, às regras jurídicas que permeiam as relações comerciais internacionais, incluídas aí as regras atinentes à arbitragem.

$\mathrm{Na}$ seara internacional é pacífico o reconhecimento da arbitrabilidade objetiva, ou seja, a envergadura do Estado de admitir uma convenção de arbitragem comercial internacional. Mesmo nas legislações mais rígidas a este respeito, como a Francesa, e.g., este reconhecimento encontra-se pacificado.

A legislação suíça de 1987, em seu artigo 177(2), assevera que "se uma das partes da convenção de arbitragem é um Estado, uma empresa controlada ou uma organização controlada por este, essa parte não poderá invocar seu próprio direito para contestar a arbitrabilidade de um litígio ou sua capacidade de ser parte em uma arbitragem".

\subsubsection{A Posição Política}

Para a parcela publicista da doutrina os contratos de estado submetidos à arbitragem devem ser vistos com granus satis. Assim, há de sempre se reconhecer o interesse público, comum ou coletivo ${ }^{12}$ que serve de escopo e baldrame para a atuação daquela determinada pessoa de direito público.

${ }^{11}$ HUNTER, M. e REDFERN, A. Op cit. p. 31.

Revista Brasileira de Direito Internacional, Curitiba, v.2, n.2, jul./dez.2005 
Portanto, ainda que o Estado, sob quaisquer de suas formas de emanação, adentrar no cenário do comércio internacional, não implica que este tenha sua conduta pautada em total consonância com a lex mercatoria, com o comércio internacional e com os lucros a qualquer custo. O Estado, por exemplo, não firma um contrato internacional, com finalidade exclusivamente econômica, há sempre o interesse público envolvido.

Os causídicos desta postura aduzem, em suma, que as pessoas jurídicas de direito público e os comerciantes internacionais não são categorias equiparáveis já que possuem objetivos drasticamente diversos na cena comercial internacional.

\subsubsection{A Terceira Via}

Hodiernamente já desenha-se no plano internacional privado uma linha doutrinária mais amena da política que visualiza a possibilidade da arbitragem internacional nos contratos de estado.

Para esta parcela da doutrina 0 instituto da arbitragem deveria se amoldar as vicissitudes próprias dos contratos de Estado uma vez que estes realmente não se encontram em patamar idêntico aos comerciantes internacionais.

Contemporaneamente não é o que tem ocorrido. No comércio internacional o que se vislumbra é a aplicação direta das regras arbitrais sem nenhuma ressalva tendo em vista as pessoas jurídicas de direito público.

A justificação para tal reside no fato de:

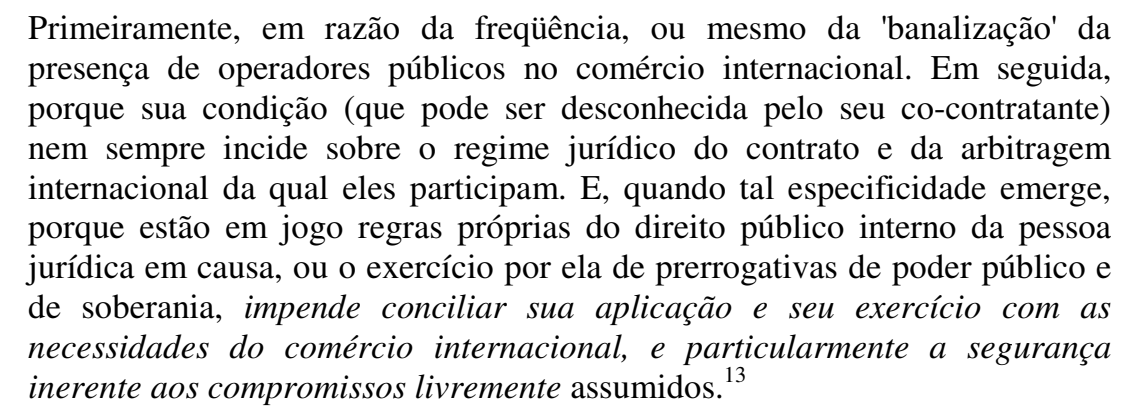

${ }^{12} \mathrm{CF} / 88$.

${ }^{13}$ FOUCHARD, PH. Et ali. Traité de l'arbitrage commercial international. Paris: Litec, 1996. p. 46.

Revista Brasileira de Direito Internacional, Curitiba, v.2, n.2, jul./dez.2005 
Esta posição vigorante baseia-se no fato que as prerrogativas adquiridas pelo Estado não poderiam cercear ou modificar os direitos adquiridos por uma empresa estrangeira.

\subsection{A CLAUSULA COMPROMISSÓRIA}

Todos os contratos firmados entre pessoas jurídicas de direito público e particulares são marcados, fundamentalmente, por disposição denominada clausula compromissória.

Esta cláusula refere-se acerca da situação processual que envolve as obrigações pactuadas. Ou seja, "objetiva assegurar a imparcialidade na resolução de controvérsias, constituindo garantia que o próprio Estado está interessado em prover" ${ }^{\prime 14}$.

A segurança das relações internacionais é um dos princípios basilares que guiam as instituições arbitrais. Neste influxo, Eric Loquin ${ }^{15}$ afirma que o princípio da eficácia da cláusula compromissória constituí, em conjunto com aquele primeiro enunciado axiológico, alicerces necessários para a arbitragem nos contratos de Estado.

No contexto da arbitragem comercial internacional, a eficácia das cláusulas compromissórias abarcadas nos contratos envolvendo uma pessoa jurídica de direito público é conditio sine qua non para assegurar a segurança das operações comerciais internacionais.

Nesta toada, a imperatividade das cláusulas compromissórias é requisito indispensável quando se trata da arbitrabilidade subjetiva.

\subsection{A ARBITRABILIDADE SUBJETIVA}

Arbitrabilidade subjetiva é à capacidade do Estado e de suas

\footnotetext{
${ }^{14}$ Id. p. 70.

${ }^{15}$ LOQUIN, E. La realité des usages du comerse intertional. Revue Internationale de Droit Économique 16.
}

Revista Brasileira de Direito Internacional, Curitiba, v.2, n.2, jul./dez.2005 
emanações de recorrer à arbitragem ${ }^{16}$.

Para parte da doutrina a conjectura de um Estado figurar enquanto pólo de uma relação jurídica de arbitragem diria respeito a capacidade das partes e não a uma questão de arbitrabilidade.

Por sob esta ótica, os litígios resolver-se-iam pela lei aplicável ao contrato. Conforme já estudado, no sistema românico a capacidade é regida pela lei da nacionalidade da pessoa, já no sistema inglês é regida pelo domicílio

Tentando evitar este conflito, as aporias que dele emergem, a doutrina internacional dominante tentou guiar esta discussão pela via da arbitrabilidade subjetiva.

Neste sentido, a capacidade de uma pessoa de direito público submeter-se à arbitragem será conduzida pela lei aplicável à convenção de arbitragem.

Esta é a posição que a $\mathrm{CCl}$ advoga. Para escorar tal ordem de idéias, que é pacífica jurisprudência internacional, que os árbitros $\mathrm{CCl}$ alvitraram dois funda- mentos. a ordem pública internacional e a boa-fé.

Todavia, esta questão está longe de ser resolvida, especialmente no que diz respeito aos países que adotam uma postura mais rígida no que diz respeito à submissão estatal à arbitragem, como a França e a Colômbia. Estes países apresentam imensas barreiras à arbitrabilidade subjetiva, pois, mantém a jurisdição administrativa à parte.

A arbitrabilidade subjetiva ainda é assunto delicado na doutrina brasileira. Todavia, está longe das dificuldades levantadas pelo exmplo francês à submissão do Estado à arbitragem.

No Mercosul, e de maneira especial no Brasil e na Argentina, a arbitrabilidade subjetiva é tolhida pela construção jurídica referente ao contrato administrativo. Nesses casos, o Estado não possui autonomia para celebrar convenção de arbitragem nos contratos administrativos.

Assim, nos integrantes do cone-sul, a arbitrabilidade é determinada em função da definição do contrato administrativo. Todavia, a noção desta

${ }^{16}$ ROMERO, E.S. Ibid. p. 264.

Revista Brasileira de Direito Internacional, Curitiba, v.2, n.2, jul./dez.2005 
categoria jurídica não possui contornos bem precisos, "se amplia ou se restringe de acordo com as oscilações políticas entre o protecionismo e o liberalismo dos países em vias de desenvolvimento"17.

O entendimento da Corte Internacional de Arbitragem, neste sentido, tem se balizado no artigo 6(2) do Regulamento:

\begin{abstract}
Se o Requerido não apresentar sua defesa, de acordo com o estabelecido no artigo 5, ou se uma das partes formular uma ou mais exceções quanto à existência, validade ou escopo da convenção arbitral, a Corte poderá decidir, sem prejuízo de admissibilidade da exceção ou das exceções, que a arbitragem poderá prosseguir se estiver convencida, prima facie, da possível existência de uma convenção de arbitragem conforme o Regulamento. Neste caso, qualquer decisão quanto à jurisdição do próprio tribunal arbitral deverá ser tomada pelo próprio tribunal. Se a Corte não estiver convencida desta possível existência, as partes serão notificadas de que a arbitragem não poderá prosseguir. Neste caso, as partes conservam o direito de solicitar uma decisão a qualquer tribunal competente sobre a existência ou não de uma convenção de arbitragem que as obrigue.
\end{abstract}

Acerca desta controvérsia, poder-se-ia colher do direito francês, nomeadamente da experiência advinda do célebre caso Myrtoon Steam Ship, elementos importantes para auxiliar a presente reflexão.

Alguns Estados, a exemplo da república francesa, não admitem a participação do Estado no procedimento arbitral. Há na legislação francesa expressa proibição legal neste sentido ${ }^{18}$.

Todavia, a Corte de Cassação francesa já decidiu que este impedimento refere-se exclusivamente ao plano interno, não abrangendo os casos de contratos internacionais.

Esta posição doutrinária foi consolidada com o julgamento do caso Myrtoon Steam Ship, em 10 de abril de 1957.Neste caso, o Estado francês fretou cargas, em missão de transporte marítimos, que deveriam serem levadas de Londres à França, firmando cargas partidas que continham cláusula compromissória.

Supervinda dissidência entre as obrigações das partes, o armador acionou o Tribunal arbitral. O Estado francês recusou-se à participar da arbitragem tendo em vista o impedimento expresso da lei.

\footnotetext{
${ }^{17}$ Id. P. 269.

${ }^{18}$ Art. 83 e 1009 do Código de Processo Civil Francês.
}

Revista Brasileira de Direito Internacional, Curitiba, v.2, n.2, jul./dez.2005 
Entretanto, a Corte de Paris declarou que "a proibição feita ao Estado de se comprometer é limitada aos contratos de ordem interna e não tem aplicação às convenções de caráter internacional".

Assim sendo, embora circunstancial esta decisão possui ressonância no comércio internacional, servindo de paradigma e precedente para os contratos posteriores. Deste modo, os contratos de Estado com particulares, na cena comercial internacional, não se regem por disposições internas daquele país, a não ser que expressamente disposto no contrato, mas sim, pelas normas, usos e costumes internacionais.

\subsection{OBJETO DO CONTRATO: DISTINÇÃO FUNDAMENTAL}

Em consonância com José Carlos de Magalhães o viés objetivo é um dos aspectos mais importantes pelos quais os contratos internacionais que envolvam pessoas jurídicas de direito público devem ser vislumbrados.

Portanto, se o Estado ingressa em relação, ainda que comercial internacional, de direito público, o contrato é regido por normas de direito administrativo havendo, desta maneira, a incapacidade deste enquanto parte da arbitragem. Neste caso, "prepondera o poder político do Estado, em sua condição de organização política da comunidade internacional"19.

Situação diversa é aquela em que o Estado pratica ato de natureza privada, "situado na ordem privada e franqueado aos particulares" ${ }^{20}$. Neste cenário, a pessoa jurídica de direito público é equiparada ao particular sendo esta relação regida não mais pelo direito administrativo, mas sim, pelo direito comercial.

Nesta última hipótese há plena capacidade do Estado submeter-se a convenção arbitral, pois, em que pese subjetivamente a relação ser de natureza publica, tendo em vista seu aspecto objetivo, reger-se-á por disposições de direito privado.

\footnotetext{
${ }^{19}$ MAGALHÃES. Op cit. P. 73.

${ }^{20}$ Id.
}

Revista Brasileira de Direito Internacional, Curitiba, v.2, n.2, jul./dez.2005 


\title{
2.6 EFEITOS DA ARBITRAGEM
}

A finalidade precípua da instituição arbitral é, nas palavras de Romero "a obtenção de uma decisão final quanto ao litígio que seja suscetível de execução ou, retomando os termos do Regulamento, de sanção legal" ${ }^{\prime 1}$.

Tendo em vista a mantença da segurança do juízo arbitral, cogita-se o requerimento de medidas conservatórias ou provisórias para fazer valer as decisões. $O$ artigo 23 do Regulamento possibilita as partes a solicitar a cessão de efeitos conservatórios ou provisórios perante o tribunal arbitral.

A interrogação levantada pela doutrina é se tais medidas se põem, e em caso afirmativo com que eficácia, em relação às pessoas jurídicas de direito público.

Dentre todas as dificuldades no que se refere à arbitragem nos contratos de Estado, esta questão é uma das mais difíceis, pois, extremamente política. Equilibra-se entre os interesses do comércio internacional e os valores políticos do interesse público.

Para os países que assumem a dicotomia francesa entre direito privado e direito administrativo, não é plausível que se acolha que um tribunal arbitral privado possa outorgar medidas conservatórias ou provisórias em favor de outrem privado, em detrimento de uma pessoa jurídica de direito público pertencente a esse Estado.

A doutrina ainda diverge acerca da temática:

\begin{abstract}
A validade de uma cláusula contratual dando competência a um terceiro para determinar medidas provisórias ou conservatórias com relação a uma pessoa jurídica de direito público não é, contudo, pacífica, a nosso ver. A oposição entre os interesses do comércio internacional e o interesse público torna altamente arriscada e discutível a outorga de medidas conservatórias ou provisórias contra uma entidade pública por um juiz privado, árbitro ou terceiro, antes do início de uma arbitragem relativa a um contrato de Estado, ou no curso de procedimento arbitral. ${ }^{22}$
\end{abstract}

Poder-se-ia considerar que a Corte de Cassação francesa eleva o artigo 24 do Regulamento de 1988 a princípio geral do direito do comércio

\footnotetext{
${ }^{21}$ Id. P. 271.

${ }^{22}$ Id. P. 273.
}

Revista Brasileira de Direito Internacional, Curitiba, v.2, n.2, jul./dez.2005 
internacional, ou, em outras palavras, em um dos princípios da lex mercatoria.

Consolida o art. 24 do ordenamento:

\begin{abstract}
Viola os princípios do direito internacional regendo as imunidades dos Estados estrangeiros e o art. 24 do regulamento de arbitragem da Câmara de Comércio Internacional a decisão que, para determinar a anulação da penhora, entende não estar estabelecido que o Estado em causa tenha renunciado à imunidade de jurisdição, quando o compromisso assumido pelo Estado signatário da cláusula de arbitragem executar a sentença nos termos do art. 24 do Regulamento de Arbitragem da CCI implicava renúncia por este Estado da execução.
\end{abstract}

Infere-se daí que a $\mathrm{CCl}$ almejou com tal disposição a tutela da segurança dos contratos internacionais e a moral contratual e boa-fé, entrevendo a eficácia da convenção arbitral na resolução dos litígios do Estado.

Contudo, neste campo brotam mais dúvidas que respostas que, pela configuração do cenário internacional, estão longe de serem respondidas de modo definitivo e satisfatório.

Delineados os contornos teóricos atinentes a este campo de investigação, convém agora esboçar a prática arbitral internacional em contratos que envolvam pessoas jurídicas de direito público.

\title{
3 O SISTEMA DA CÂMARA INTERNACIONAL DE COMÉRCIO NO QUE SE REFERE AOS CONTRATOS DE ESTADO
}

A Corte Internacional de Arbitragem da Câmara de Comércio Internacional, em conjunto com seu Regulamento, tem sido precursores de maneira direta e reflexa dos baldrames que se encontram consolidados nas principais legislações e tratados nesta seara.

Horacio Grigera Naon ressalta a influência das práticas arbitrais da $\mathrm{CCl}$ em relação aos países latino-americanos:

\footnotetext{
Estas nuevas realidades em la region así como la presencia desde ya hace largo tiempo Del arbitraje CCI em América Latina y la relacion histórica entre sus orígenes y el desarolle Del arbitraje comercial em esta parte Del mondo permiten considerar com optimismo la evolucion Del arbitraje CCI em América Latina em los años futuros. Las estadísticas para 1996 indican que el $11,5 \%$ de las partes en arbitrajes CCI iniciados en ese ano (1997) son
}

Revista Brasileira de Direito Internacional, Curitiba, v.2, n.2, jul./dez.2005 
latinoamericanas. ${ }^{23}$

Apesar de sua vinculação a Câmara de Comércio Internacional, a Corte de Arbitragem é organismo autônomo e independente no que diz respeito ao seu desempenho, organização e funções. É composta por 63 membros atualmente de todas as partes do mundo.

De fato, a vinculação orgânica da Corte Internacional de Arbitragem com a $\mathrm{CCl}$ é que seus membros são nomeados pelo Conselho da $\mathrm{CCl}$. Assim sendo, apesar de livre, a Câmara de Comércio possui grande influência na Corte uma vez que os nomeia.

A Corte Arbitral da $\mathrm{CCl}$ é o exemplo mais bem sucedido no mundo, em termos de quantidade e efetividade das decisões, em experiências com juízo arbitral. Entretanto, válido lembrar que

\footnotetext{
la Corte no es en realidad tal, ni mucho menos un tribunal arbitral, pues no actúa ni puede ser designada como árbitro ni decide casos arbítrales. La corte se limita a administrar arbitrajes interviniendo exclusivamente en las oportunidades previstas en el Reglamento. Es la Corté quien tiene a su cargo el nombramiento o conformación de los árbitros que habrán de resolver el caso sometido a arbitraje conforme al Reglamento. ${ }^{24}$
}

O sucesso desta experiência também deriva, em larga escala, da flexibilidade que a Corte Arbitral dispõe para responder de modo mais eficiente e satisfatório de praticamente todas as situações presentes no mercado global.

É justamente neste influxo que a $\mathrm{CCl}$ tem obtido bons resultados nas arbitragens que envolvem em um de seus pólos uma entidade pública. Ao contrário dos arranjos doutrinariamente delineados (político e econômico) não abarcam, de modo pleno e satisfatório, as peculiaridades e os paradoxos advindos da arbitragem dos contratos de Estado.

$\mathrm{O}$ direito internacional privado, em matéria de arbitragem comercial internacional, precisa ter em mente a noção político-jurídica de interesse público, fim último do Estado.

A questão que se põe, porém, no cenário do comércio global é se a

\footnotetext{
${ }^{23}$ NAÓN, H. G. El funcionamiento de las Reglas de Arbitraje de la Cámara de Comercio Internacional. In: GARCÉS, J. M. A Arbitragem na Era da Globalização. Rio de Janeiro: Forense, 1997. p. 204.
}

Revista Brasileira de Direito Internacional, Curitiba, v.2, n.2, jul./dez.2005 
Câmara Internacional está suficientemente preparada para atender as vicissitudes derivadas das operações comerciais internacionais em frente ao interesse público.

Sigvard Jarvin, então conselheiro geral na Corte de Arbitragem, já prevendo este debate em 1985, aludia ao procedimento diferenciado dispensado aos negócios arbitrais que envolvessem um Estado. Nesta toada, segundo o conselheiro, "a Corte de Arbitragem teria notadamente tratado de uma maneira especial a falta total de participação na arbitragem de uma parte estatal, sua presença apesar dela no procedimento, sua contestação de existência ou de validade da convenção de arbitragem e a independência dos árbitros designados por essa parte". ${ }^{25}$

Com o respaldo de seus oitenta anos de bagagem teórica e prática, a Câmara de Comércio Internacional obteve êxito ao adequar o procedimento arbitral às pessoas de direito público. Tais afirmações são alicerçadas por numerosos precedentes. ${ }^{26} \mathrm{O}$ número é ainda maior em se tratando dos países denominados em desenvolvimento, como o Brasil.

Assim, a $\mathrm{CCl}$ vai se firmando no cenário internacional enquanto paradigma no que tange à prática arbitral nos contratos de estado garantindo a segurança necessária para a resolução destes conflitos econômicos. Conforme afirma Romero:

\begin{abstract}
A universalidade e a flexibilidade 16 do regulamento de arbitragem da CCI, e notadamente o de 1998 (doravante o "Regulamento"), permitiram à Corte Intemacional de Arbitragem, aos árbitros CCI e aos juízes estatais de desenvolver uma prática da arbitragem comercial internacional em matéria de contratos de Estado que leva em consideração, ao mesmo tempo, os interesses da arbitragem comercial internacional, inclusive a segurança dos intercâmbios internacionais, e do interesse público que os Estados e suas emanações devem expressamente proteger. ${ }^{27}$
\end{abstract}

\footnotetext{
${ }^{24}$ NÁON, H. G. Ibid. p. 205.

${ }^{25}$ ROMERO, E.S.lbid. p. 262.

${ }^{26} 67$ dos 541 pedidos de arbitragem submetidos à Corte em 2000 envolveram uma ou diversas entidades públicas ou serni-públicas; dos 566 casos de arbitragem registrados em 2001,49 envolveram partes estatais ou semi-públicas provenientes da Europa Central e do Leste, da Ás do Sul e do Leste, da África Sub-Sariana e da América Latina.

${ }^{27}$ Ibid. p. 263.
}

Revista Brasileira de Direito Internacional, Curitiba, v.2, n.2, jul./dez.2005 


\subsection{ENFIM, COMO FICA A QUESTÃO?}

A finalidade do aparelho estatal - o interesse público - deve levada em consideração quando da análise da formação da convenção de arbitragem, da constituição do tribunal arbitral e do exame preliminar da sentença arbitral.

Deste modo, a prática da Corte Internacional de Arbitragem visa levar em conta o interesse público protegido pelas partes. Assim o faz permeada pela noção de confiança para atrair uma parte estatal muitas vezes hostil ao procedimento arbitral.

São três, segundo Romero ${ }^{28}$, as medidas neste sentido: a determinação do número de árbitros, a independência destes e nomeação de um árbitro no lugar da parte estatal recalcitrante.

\subsubsection{O NÚMERO DE ÁRBITROS}

Comumente o número de árbitros é fixado é fixado na convenção de arbitragem. O procedimento geralmente adotado é a submissão dos litígios a um tribunal arbitral composto por uma tríade de juízes.

Todavia, nos casos em que não há esta pré-fixação a corte determina a presença de apenas uma árbitro, salvo se prejudicial às partes. Nos casos complexos, todavia, a corte prevê a nomeação de tr6es árbitros.

Dentre as causas consideradas complexas, a $\mathrm{CCl}$ entende que as causas que envolvem uma parte estatal podem ser consideradas complexas. A complexida decorre do fato que estas situações implicam: "I -problemas complicados relativos à competência do tribunal arbitral; II - a aplicação de regras imperativas do Estado ou da pessoa jurídica em questão; III - riscos para toda uma população e IV - a interferência de interesses e forças políticas"29.

\footnotetext{
${ }^{28}$ Id. P. 289

${ }^{29}$ Id. P. 290.
}

Revista Brasileira de Direito Internacional, Curitiba, v.2, n.2, jul./dez.2005 


\subsubsection{INDEPENDÊNCIA DOS ÁRBITROS}

A imparcialidade do arbitro é pressuposto necessário e cogente para o juízo arbitral. Imparcialidade, neste sentido, é posta, sobretudo, no sentido de independência, nomeadamente independência econômica.

Entretanto, no que diz respeito aos árbitros indicados pelo Estado, a Corte Arbitral, ao nosso ver absurdamente, analisa com menor austeridade sua imparcialidade.

Geralmente este esforço que obter a confiança da parte estatal é feito com a designação de uma parte que compartilhe com ele da mesma cultura e costumes.

\subsubsection{NOMEAÇÃO DO ÁRBITRO PELA CCI}

Quando a Corte Internacional tiver que nomear um árbitro no lugar de uma parte que se eximiu de assim proceder, nos casos em que envolvam pessoas jurídicas de direito público, haverá um procedimento especial.

Primeiro, um dos membros eleitos será de cultura semelhante a parte estatal. Em segundo lugar, a $\mathrm{CCI}$ pode nomear diretamente quem the pareça melhor indicado para o caso. Por fim, se a Corte não encontrar candidato apto escolherá algum árbitro da região ou país de cultura semelhante.

Traçadas as linhas gerais do procedimento arbitral desenvolvido pela $\mathrm{CCl}$ faz-se necessária, por fim, a análise prática e teórica da questão a luz da doutrina e experiências brasileira.

\section{OS CONTRATOS DE ESTADO EM JUÍZO ARBITRAL: A EXPERIÊNCIA BRASILEIRA}

A discussão acerca da participação de entes estatais em juízos arbitrais na doutrina nacional espelha àquela dicotomia entre a posição econômica e a posição política dos doutrinadores.

Em que pese esta indefinição teórica, na prática, o Estado brasileiro 
ainda se encontra avesso à prática arbitral, tanto no plano interno quanto no plano internacional.

Destarte, tentando elucidar estar questão, parece-nos relevante estudo de um caso concreto que envolve uma pessoa jurídica de direito público brasileira, a Companhia Paranaense de Energia Elétrica, COPEL.

A COPEL firmou com outra empresa, a UEG - Araucária, contrato para a construção de uma usina elétrica à gás na região metropolitana do Estado do Paraná. Neste contrato encontra-se presente cláusula compromissória elegendo como foro arbitral a Corte Internacional de Arbitragem da $\mathrm{CCl}$ em Paris.

A UEG é empresa brasileira, porém, cujo capital majoritário é estrangeiro. A COPEL, como é sabido, é sociedade de economia mista sob a forma de sociedade anônima cujo acionista majoritário é o Estado do Paraná.

No desenrolar do projeto, todavia, descobriu-se que o gerador de energia em construção era incompatível com o sistema elétrico nacional. Deste modo, adaptações foram feitas para a compatibilização do funcionamento do gerador, entretanto, esta apenas poderia funcionar em um regime de "ilhamento".

Após, revelou-se que não era necessária a reforma procedida para a harmonização do gerador com o sistema nacional, mas sim, ajustes menores.

Havia no contrato firmado cláusula expressa que identifica a COPEL enquanto responsável por todos estes desajustes estruturais.

Deste modo, a UEG - Araucária formulou requisição de arbitragem junto à "International Court of Arbitration of the International Chamber of Commerce", tendo como reclamada a COPEL.

$O$ pleito formulado se baseia em três argumentos fulcrais, que implicariam, segundo a UEG, a caracterização de conduta de inadimplemento pela COPEL.

a) O não pagamento pela COPEL dos valores pretensamente referentes ao mês de janeiro, por 45 dias;

Revista Brasileira de Direito Internacional, Curitiba, v.2, n.2, jul./dez.2005 
b) A "mudança de lei" - ou se sua interpretação - que, seria supostamente inferida dos atos praticados pelo Governador do Estado do Paraná;

c) A ocorrência de "ato de Governo" ou "evento de governo", que consistiria na solicitação remetida à ANEEL por volta do dia 09 de dezembro de 2002, pelo então Governador Eleito, solicitando que a Agência suspendesse o exame relativo ao pedido de homologação do PPA.

Com base nos fundamentos arrolados, pretende a UEG obter ressarcimento por prejuízos no valor de $\mathrm{R} \$ 69.665 .969,97$, mais as parcelas vincendas e correção monetária, pagáveis em dólares americanos. Esses valores se referem ao montante pretensamente devido pela COPEL em virtude de suposta obrigação de pagar mensalmente por toda a potência inicial assegurada produzida pela usina desde o mês de janeiro de 2003.

Observe-se que a Araucária requer a realização dos pagamentos, mas não requer a extinção do contrato. Reservou-se a UEG, por isso, o direito de complementar seu pedido com os valores decorrentes da resolução do contrato, quais sejam, o valor mais elevado entre o Valor de Mercado da Usina e o pagamento mensal pretensamente devido à UEG até os limites previstos no PPA.

Em resposta, a COPEL suscitou a preliminar de nulidade da cláusula compromissória e, conseqüentemente, impossibilidade de submissão deste litígio ao juízo arbitral da $\mathrm{CCl}$, conforme previsão contratual.

A defesa da companhia paranaense baseia-se na inexistência de lei estadual específica regulamentadora da matéria. Destarte, sendo a COPEL sociedade de economia mista com capital majoritário estatal apenas o Estado poderia autorizar a inclusão da cláusula compromissória no contrato firmado.

Todavia, esta autorização estatal necessária só é realizada através do Poder Legislativo, através de lei. Assim sendo, como inexiste lei específica neste sentido, alega o Poder Público a inarbitrabilidade da COPEL nesta situação específica.

Em apreciação liminar, a posição da Corte Internacional de Arbitragem da $\mathrm{CCl}$ foi de afastar o entendimento do Estado do Paraná tendo em vista a 
boa-fé e segurança que regem os procedimentos arbitrais comerciais internacionais.

A participação da Corte Internacional, entretanto, resignou-se apenas uma apreciação inicial, e em caráter de urgência. O desenvolvimento do litígio acabou por não ser analisado de maneira mais aprofundada pelos membros desta Corte haja vista acordo fixado entre as partes.

A análise deste caso concreto específico bem demonstra a situação da temática na doutrina brasileira: in casu e sem baldrames e alicerces préfixados.

\section{CONCLUSÃO}

Tendo sido percorrido o caminho proposto o trabalho aponta para o conjunto de conclusões que emergem do texto apresentado.

Os contratos internacionais de Estado submetidos à arbitragem oscilam entre duas posições antagônicas: a opção econômica e a opção política. No cenário mundial, em que pese os novos imperativos da economia mundial globalizada, a posição política ainda parece-nos dominante.

Não encontramos na doutrina do direito internacional privado resposta satisfatória que atenda aos anseios do Estado e também do mercado. Esta ausência de fundamentação acaba por gerar na prática grande insegurança no que diz respeito aos contratos de Estado, sentimento incompatível com a prática arbitral.

A ausência de respostas teóricas, todavia não se reproduz na prática. A CCl, lastreada no princípio da confiança, soube ponderar os paradoxos constitutivos da temática e sopesar o interesse das partes da arbitragem nos contratos que envolvem pessoa jurídica de direito público.

No que concerne a experiência pátria, tanto em termos teóricos quanto na práxis, ainda subsistem mais interrogações do que respostas no que diz respeito a participação dos Estados ou entidades estatais em juízos arbitrais. A esta indefinição soma-se um sentimento de rejeição por grande parte da doutrina brasileira do juízo arbitral. É este o cenário que abrolha na prática em 
situações como a da Companhia Paranaense de Energia Elétrica acima disposta.

Para além do exposto, espera-se que o trabalho tenha logrado êxito na tarefa de demonstrar o caminho entre o discurso teórico e a prática efetiva da prática arbitral em contratos de Estado, exigindo um crescente aprofundamento crítico, permitindo, assim, desenvolvimento para além de uma obra.

Finalmente, se este trabalho contribuir para a percepção da problematização de alguns dos inúmeros aspectos que implica o estudo do direito à vida, terá, então, cumprido seu papel.

\section{REFERÊNCIAS}

ALMEIDA, R. R. Arbitragem Interna e Internacional. Rio de Janeiro: Renovar, 2003.

ARAÚJO, NADIA. Direito Internacional Privado: teoria e prática brasileira. Rio de Janeiro: Renovar , 2003.

CORNU, G. Vocabulaire Juridique. Paris: PUF, 2003.

FOUCHARD, PH. Et ali. Traité de l'arbitrage commercial international. Paris: Litec, 1996.

GUERREIRO, J.A.T. Arbitragem nos Contratos com o Estado: Direito Brasileiro e Direito Comparado. 1ํㅗㄴ Seminário Internacional sobre Direito Arbitral. Belo Horizonte: Câmara de Arbitragem de Minas Gerais, 2003.

HUNTER, M.e REDFERN, A. Law and Pratice of International Commercial Arbitration. London: Sweet \& Maxwell, 1986.

KROETZ, T. A. Arbitragem: Conceito e Pressupostos de Validade. Dissertação apresentada como requisito parcial a obtenção do grau de mestre. São Paulo: PUC, 1996.

LOQUIN, E. La realité des usages du comerse intertional. Revue Internationale de Droit Économique 16.

MAGALHÃES, J. C. Arbitragem Comercial. Rio de Janeiro: Freitas Bastos. 1986.

NAÓN, H. G. El funcionamiento de las Reglas de Arbitraje de la Cámara de Comercio Internacional. In: GARCÉS, J. M. A Arbitragem na Era da Globalização. Rio de Janeiro: Forense, 1997.

Revista Brasileira de Direito Internacional, Curitiba, v.2, n.2, jul./dez.2005 
MANN, F. A. State Contracts and International Arbitration. Nova Iorque: Studies of International Law, s.d.

MELO, C. D. A. Curso de Direito Internacional Público. Rio de Janeiro: Renovar, 2001.

OPPETIT, B. Théorie de l'arbitrage. Paris: PUF, 1998.

ROMERO, E.S. A Arbitragem da Câmara de Comércio Internacional e os Contratos de Estado. In: Revista de Direito Bancário do Mercado de Capitais e da Arbitragem n ${ }^{\circ}$ 19. São Paulo: RT, jan-mar de 2003.

SOARES, G. F. Concessões de Exploração de Petróleo e Arbitragens Internacionais. São Paulo: José Bushatsky, 1997. 